\title{
O varejo de moda e a criação de valor com produtos sustentáveis: um estudo de casos múltiplos
}

\author{
The Fashion Retail and the value creation with sustainable \\ products: a multiple case study
}

\section{Eleonora Alves Baptista} Mestre em Administração (IBMEC-RJ) ellealves@hotmail.com

\section{Edson José Dalto}




\section{O varejo de moda e a criação de valor com produtos sustentáveis: um estudo de casos múltiplos \\ The Fashion Retail and the value creation with sustainable products: a multiple case study}

Eleonora Alves Baptista e Edson José Dalto

\section{Resumo}

Este estudo tem o objetivo de compreender como o desenvolvimento de produtos sustentáveis em empresas brasileiras de confecção e varejo de moda pode criar valor para as próprias firmas, para a sociedade e para o meio ambiente. A pesquisa coletou informações primárias de quatro empresas fluminenses, com observação direta e entrevistas com diretores das firmas, obtendo dados secundários em relatórios setoriais e outros documentos. Este estudo de casos múltiplos foca em três dimensões gerais de pesquisa - gestão socioambiental, criação de valor e desenvolvimento de produtos em empresas de fast fashion -, codificadas em sete categorias que, ao serem analisadas em síntese cruzada de dados, elucidam as seguintes conclusões: (1) as firmas não possuem visão integrada dos domínios econômico, ético e legal; (2) as empresas não acreditam que o mercado consumidor de moda valorize práticas socioambientais e, assim, não se motivam a investir em práticas e produtos; (3) a cadeia produtiva fragmentada dificulta o controle de atividades e aparece como um dos principais entraves para o desenvolvimento de produtos sustentáveis; (4) o acesso a informações sobre melhores práticas socioambientais e incentivos fiscal são importantes mecanismos indutores para alavancar o desenvolvimento de produtos sustentáveis; (5) o desenvolvimento de capacidades estratégicas na área de prevenção de poluição, manejo de produtos e tecnologia limpa criam valor para a cadeia produtiva.

Palavras- chave: moda; fast fashion; criação de valor; produtos sustentáveis.

\begin{abstract}
This study aims to understand how the development of sustainable products in Brazilian fashion retail businesses creates value for the companies themselves, society and the environment. A qualitative approach to multiple case study method investigates practices and processes at four companies from Rio de Janeiro State. The study collected primary information from direct observation and interviews with the firms' directors, and secondary data from industry reports and other documents. Three overall dimensions of the study - environmental management, value creation and product development in fast fashion companies - encoded into seven categories, when considered in data crosssynthesis, elucidate the following conclusions: (1) the firms do not have economic, ethical and legal fields integrated view; (2) the companies do not believe that the fashion consumer market values environmental practices and thus not motivated to invest in practices and products; (3) a fragmented supply chain makes it difficult to control activities and appears as a major constraint to the development of sustainable products; (4) access to information on best environmental practices and tax incentives are important inductors' mechanisms to leverage the development of sustainable products in the Brazilian fashion retail; (5) the development of strategic capabilities in pollution prevention area, management products and clean technology create value for the production chain.
\end{abstract}

Keywords: fashion; fast fashion; value creation; sustainable products. 


\section{INTRODUÇÃO}

$\mathrm{Na}$ virada do milênio, as empresas brasileiras de médio porte que atuavam no mercado de varejo de moda adotaram o modelo de negócios conhecido por fast fashion, cuja proposta é oferecer rapidamente as tendências de moda e aumentar as margens de lucro para os varejistas. Esse modelo de operação impacta diretamente no aumento do volume comercial do setor têxtil e de confecção que, em 2012, movimentou cerca de US\$ 744 bilhões entre países (ABIT, 2014). O setor participa com 5,5\% da receita líquida da indústria de transformação do Brasil, representa 3,5\% do PIB e produz 9,8 bilhões de peças/ano, ocupando a quarta posição no ranking mundial dos produtores de confecção (ABIT, 2014, 2015; IEMI, 2014).

Em uma visão ampliada pelo cenário global, o desenvolvimento, sinônimo de um modelo de crescimento baseado na industrialização, nos resultados financeiros e na expansão para novos mercados compromete a vida no planeta, afeta a manutenção dos recursos naturais para gerações futuras e impacta negativamente a economia de muitas nações (MCDONOUGH e BRAUNGART, 2008).

Desde os anos 1990, esses impactos são discutidos pela academia, governos e sociedade civil que se engajam em planos de ação, novos modelos de atuação e compromissos de responsabilidade socioambiental (SACHS, 2007). As empresas se envolvem com o processo de mudança a partir da revolução da qualidade, quando passam a considerar fatores relevantes em suas condutas dentro e fora da organização (SHRIVASTAVA e HART, 1992; PORTER e VAN DER LINDE,1995; SEURING, 2004).

Novas práticas são sustentadas por instrumentos de gestão e relatórios de análise como as normas ISO 26000, GRI, indicadores de RSE, códigos de ética e conduta, entre outros (BARBIERI e CAJAZEIRA, 2012). A busca por uma conexão entre valores econômicos, sociais e ambientais - fundamentada no conceito do tríplice resultado leva as empresas a atualizarem sua visão sobre o negócio e a promoverem novos elementos de valor para todas as partes envolvidas em suas atividades (ELKINGTON, 2011; SAVITZ, 2007).

Ecoeficiência, análise do ciclo de vida de produtos, normas de conduta para com fornecedores e colaboradores, bem-estar do trabalhador e respeito ao consumidor são fatores decisivos na mudança de conduta das organizações (SEURING, 2004). 
Contudo, as empresas têxteis e de confecções ainda enfrentam dificuldades para reestruturar os negócios e sistematizar condutas responsáveis em atividades rentáveis e sustentáveis (FIKSEL, 1996; FLETCHER e GROSE, 2011). O processo de desenvolvimento de produtos (PDP) dessas empresas é pautado pelas características estético-formais das roupas e acessórios que são produzidos de maneira fragmentada, com operações internas e externas. Com isso, a gestão de desenvolvimento de produtos envolve uma cadeia extensa, interdependente e pouco sistematizada no tocante aos processos e controles (id. 1996, 2011).

Esta pesquisa visa a compreender como o desenvolvimento de produtos sustentáveis pode criar valor em empresas brasileiras de varejo de moda de médio porte. Assim, tem o objetivo específico de caracterizar as empresas no tocante às iniciativas socioambientais e identificar os principais pontos de alavancagem e entrave para o desenvolvimento de produtos sustentáveis.

Neste estudo, produtos sustentáveis referem-se a bens 'vestíveis', ou seja, roupas e acessórios que também são denominados "produtos responsáveis", “ecoprodutos” e ou "produtos limpos".

Os objetivos deste estudo são elucidados a partir da seguinte proposição: a criação de valor com o desenvolvimento de produtos de moda sustentáveis está ancorada em capacidades estratégicas aplicadas em processos responsáveis pelos quais as empresas desempenham atividades internas e externas, e pelo modo sustentável como se relacionam e interagem com seus stakeholders.

Tal proposição sustenta-se no aporte teórico derivado das ideias desenvolvidas por Elkington (2001), Sachs (2007), Hart (2004, 2006), Porter e Kramer (2011) e Manzini e Vezolli (2002), ao se tomar como premissa que a criação de valor com o desenvolvimento de produtos de moda sustentáveis está ancorada em padrões e processos pelos quais as empresas se relacionam e interagem ao longo de toda a cadeia produtiva e fundamenta-se no conceito do tríplice resultado, ao considerar novas formas de capital para reconfigurar questões econômicas, sociais e ambientais em atividades internas e externas. A fim de completar este dialogo teórico, assumem-se os pressupostos conceituais definidos por Kozlowski, Bardecki e Searcy (2012), Fernie e Azuma (2004), Bhardwaj e Fairhurst (2010) e Cietta (2010), cuja ênfase está no fato de que empresas de fast fashion atendem a um mercado com baixa previsibilidade, à 
demanda altamente volátil, ao ciclo de vida curto dos produtos de tendência e ou àqueles que são 'febre de moda'. Tais fundamentos são alinhados aos métodos aplicados em PDP elucidados por Löbach (2001), McDonough e Braungart (2008), Birkeland (2002) e Fletcher e Grose (2011).

A compreensão deste problema é abordada em uma perspectiva qualitativa que, por meio do método de Estudo de Casos Múltiplos, considera a percepção dos diretores executivos e de criação de quatro empresas brasileiras de varejo de moda sediadas no Estado do Rio de Janeiro.

Para tanto, organizou-se este artigo em cinco partes: na seção 1, o trabalho é apresentado, bem como seu contexto e relevância; na seção 2, está a revisão de literatura, que comporta conceitos sobre gestão socioambiental, geração de valor sustentável e desenvolvimento de produtos sustentáveis em empresas de fast fashion; a seção 3 descreve a metodologia aplicada na pesquisa; na seção 4, estão os estudos de caso; os resultados da síntese de casos cruzados são apresentados na seção 5. As considerações finais do estudo estão na seção 6.

\section{FUNDAMENTAÇÃO TEÓRICA}

Esta fundamentação teórica busca definições sobre gestão socioambiental, criação de valor sustentável e processo de desenvolvimento de produtos em empresas de fast fashion, que servem de base para o desenvolvimento da presente pesquisa.

\section{Gestão Socioambiental}

Uma organização sustentável é aquela que procura incorporar conceitos e objetivos relacionados ao desenvolvimento sustentável em políticas e práticas consistentes, sendo eficiente economicamente, responsável ambientalmente e justa socialmente (MALONI e BROWN, 2006; BARBIERI e CAJAZEIRA, 2012).

Savitz (2007) afirma que sustentabilidade é, na prática, a arte de fazer negócios em um mundo interdependente. Assim, as atividades empresariais são norteadas, cada vez mais, pela responsabilidade assumida não só por suas próprias atividades, mas também pelas dos fornecedores, pelas comunidades em que atuam e pelas pessoas que usam seus produtos (id., 2007). 
Este pensamento define a gestão socioambiental no modelo de gestão desenvolvido pela consultoria inglesa SustainAbility e promovido por Elkington (2011), que passa a considerar o capital natural e o capital social, além do econômico, como fontes necessárias à obtenção do lucro. Dentre os modelos criados para incorporar essa perspectiva está o que é conhecido por triple bottom line (3BL ou tríplice linha de resultados líquidos). A partir da expressão bottom line, utilizada para designar o resultado líquido de uma empresa, o modelo articula as atividades da firma (em suas diferentes formas de capital, além do econômico) para se obter resultados líquidos positivos em termos econômicos, sociais e ambientais (ZYLBERSZTAJN e LINS, 2010; BARBIERI e CAJAZEIRA, 2012). Ou seja, as empresas são desafiadas a minimizar os impactos negativos de suas operações e adotar uma postura de interação com diferentes públicos de relacionamento, buscando novas soluções economicamente viáveis para problemas sociais e ambientais (HART, 2006).

Por vezes, essa postura é associada ao conceito de Responsabilidade Social Empresarial (RSE), que implica em uma empresa se firmar de modo ético e socialmente responsável por meio de uma extensa gama de stakeholders como funcionários, consumidores, comunidades, governo, ONGs, investidores, mídia e integrantes da cadeia de suprimentos, o que fomentaria, portanto, o tríplice resultado (MALONI e BROWN, 2006; SAVITZ, 2007). A RSE é uma forma de gestão que estabelece metas empresariais focadas no desenvolvimento sustentável da sociedade, preservando recursos ambientais e culturais, respeitando a diversidade e promovendo a redução das desigualdades sociais (ETHOS, 2007).

Essas diretrizes mostram uma visão integrada de práticas e destacam o fato de que não adianta uma empresa desenvolver projetos sociais para a comunidade, se, na realização de suas atividades, polui mananciais, submete funcionários a situações inseguras de trabalho, mantém contrato com fornecedores que utilizam mão de obra infantil, não recolhe impostos devidos ou paga salários menores às mulheres do que aos homens que ocupam cargos idênticos (MALONI e BROWN, 2006).

Sen (1999 apud DAHER et al. 2007), Hart (2006) e Maloni e Brown (2006) afirmam que está na visão dos gestores o exercício da função ética de respeitar os direitos coletivos e garantir o bem-estar de todos os agentes afetados pela empresa. Assim, gestores de áreas específicas, como o departamento de desenvolvimento de 
produtos, por exemplo, devem ter atitudes responsáveis desde a escolha das matérias-

primas até o descarte dos produtos pelo consumidor, com foco na minimização ou, se possível, na eliminação da geração de resíduos (MILAN, VITTORAZZI e REIS, 2010).

\section{Criação de Valor Sustentável}

A palavra valor possui ampla gama de significados e pode ser explorada no sentido ético, jurídico, pessoal, social e econômico-financeiro, entre outros (SOUZA e ALMEIDA, 2006). Porter (1992) sugere que valor é aquilo que os compradores estão dispostos a pagar pelo que a empresa lhes oferece, ou seja, cada indivíduo estabelece o valor do produto ou serviço adquirido em função do benefício agregado por tal produto ou serviço. Para Barney (1991), o valor é um atributo do recurso para explorar oportunidades e/ou neutralizar ameaças no ambiente.

Porter (1992) chama de 'cadeia de valor' o encadeamento deste conceito em um sistema de nove atividades interdependentes, desde a fonte de matéria prima para fornecedores de componentes até a utilização do produto entregue ao consumidor final. Assim, criar uma proposta de valor pode ser entendido como o objetivo estratégico da empresa de desenvolver algo que seja estimado por um interlocutor - indivíduo, empresa ou sociedade (PORTER e KRAMER, 2011).

O conceito de criação de valor é sustentado por um modelo multidimensional que requer que as empresas levem em conta um conjunto abrangente de motivadores que alimentem as capacidades internas e engajem os constituintes externos (HART e MILSTEIN, 2004; Hart, 2006). Com a incorporação do termo 'sustentável', questões socioambientais passam a ser consideradas em todas as atividades que fornecem ou recebem valor na forma de produtos ou serviços, visando atender aos parâmetros do 3BL (SAVITZ, 2007). O conjunto de motivadores está associado a quatro estratégias, conforme apresentado na figura 1 [(HART e MILSTEIN, 2004). 
Figura 1: Modelo de Criação de Valor Sustentável

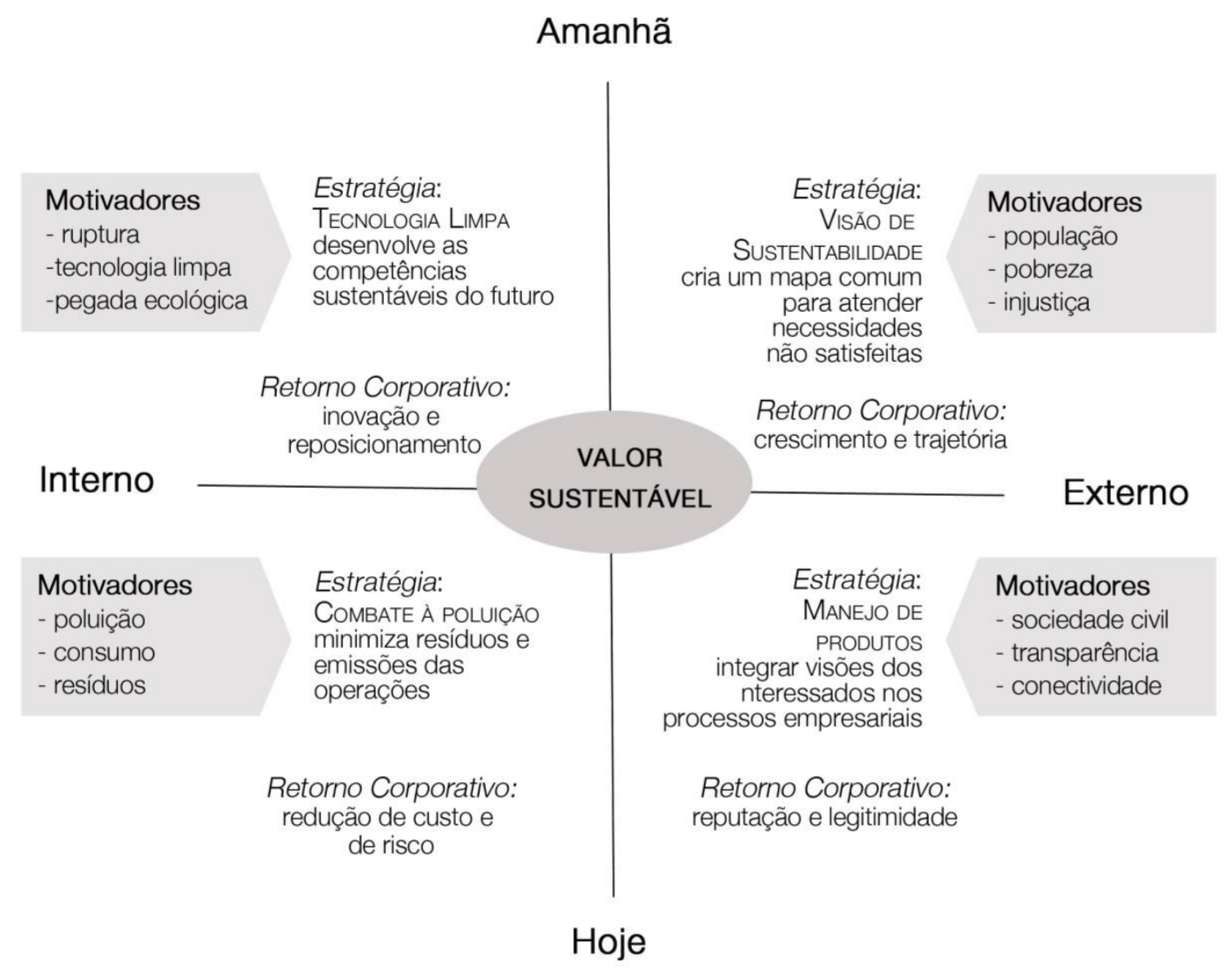

Conjunto de motivadores associados a quatro estratégias. Fonte: Hart e Milstein, 2004

Os autores (HART e MILSTEIN, 2004) afirmam que os principais resultados oriundos das atividades realizadas em cada grupo estratégico podem criar valor quando há: (1) utilização melhorada dos insumos; (2) gerenciamento de produtos associado à interação com fornecedores, clientes, órgãos de regulação, comunidades, ONGs e mídia; (3) inovação e reposicionamento com uso de tecnologias limpas; e, (4) diálogo e colaboração com stakeholders em atividades inclusivas com benefícios mútuos. Respectivamente, tais atividades criam os seguintes valores econômicos e socioambientais: custos mais baixos de matérias-primas e depósitos de resíduos; melhora nas relações comunitárias, legitimidade e reputação de marca; habilidades internas são reposicionadas e mercados futuros podem ser desenvolvidos e ou 
explorados; e, abertura de caminhos para crescimento em mercados anteriormente não atendidos ou acesso a mercados de escala e escopo imensos.

Para detectar se a estratégia das organizações tem potencial para criar valor sustentável é essencial realizar um diagnóstico simplificado (HART, 2006; SAVITZ, 2007; ZYLBERSZTAJN e LINS, 2010). Este diagnóstico proposto por Hart (1997) avalia as capacidades da empresa em ações e iniciativas internas e externas, com uma visão na atualidade e no futuro, conforme ilustrado na figura 2.

Figura 2: Diagnóstico de atividades de valor sustentável

\begin{tabular}{|c|c|c|}
\hline \multirow[t]{2}{*}{ AMANHÃ } & $\begin{array}{l}\text { TECNOLOGIA LIMPA } \\
\text { A sustentabilidade de nossos } \\
\text { produtos é limitada pela nossa } \\
\text { base de competência? }\end{array}$ & $\begin{array}{r}\text { VISÃO DE SUSTENTABILIDADE } \\
\text { Nossa visão corporativa noS } \\
\text { conduz à solução dos } \\
\text { problemas sociais e } \\
\text { ambientais? }\end{array}$ \\
\hline & $\begin{array}{l}\text { Há potencial para realizar } \\
\text { grandes melhorias por meio de } \\
\text { tecnologias inovadoras? }\end{array}$ & $\begin{array}{r}\text { Nossa visão nos concentra nas } \\
\text { necessidades não atendidas } \\
\text { das pessoas que estão na base } \\
\text { da pirâmide econômica? }\end{array}$ \\
\hline \multirow{2}{*}{ HOJE } & $\begin{array}{l}\text { PREVENÇÃO DA POLUIÇÃo } \\
\text { Onde estão as correntes de } \\
\text { resíduos e as emissões mais } \\
\text { significativas de nossas } \\
\text { operações atuais? }\end{array}$ & $\begin{array}{l}\text { MANEJO DE PRODUTOS } \\
\text { Quais serão as implicações para } \\
\text { projetos e desenvolvimento de } \\
\text { produtos se assumirmos as } \\
\text { responsabilidades pelo ciclo de } \\
\text { vida completo do produto? }\end{array}$ \\
\hline & $\begin{array}{l}\text { Podemos reduzir custos e } \\
\text { riscos ao eliminar resíduos } \\
\text { na fonte ou usá-los como } \\
\text { material útil? }\end{array}$ & $\begin{array}{c}\text { Podemos construir reputação e } \\
\text { legitimidade ao usar um leque } \\
\text { mais vasto de stakeholders? }\end{array}$ \\
\hline & INTERNO & EXTERNO \\
\hline
\end{tabular}

Avaliação das capacidades das empresas Fonte: Hart, 1997

O quadrante é analisado e as forças das capacidades estratégicas são classificadas como não existente, emergente, estabelecida e institucionalizada (HART, 1997). 


\section{Desenvolvimento de Produtos Sustentáveis}

O Processo de Desenvolvimento de Produtos (PDP) é, em linhas gerais, composto de fases sistêmicas e graduais que permeiam tomadas de decisões. Para LÖBACH (2001), o PDP é realizado em quatro fases distintas e não-separáveis: PREPARAÇÃO, com análise do problema e exigências para com o novo produto; GERAÇÃO, com alternativas de design para conceito, soluções e modelos; AVALIAÇÃO, quando a melhor solução é incorporada ao produto; REALIZAÇÃO, com aplicação da solução de design nos projetos mecânico e estrutural, desenvolvimento de modelos e registro técnico.

A esta metodologia, associam-se as atenções voltadas à redução do impacto ambiental em todo ciclo de vida do produto (MCDONOUGH e BRAUNGART, 2008; MANZINI e VEZZOLI, 2011). Assim, o meio ambiente é incorporado aos critérios de funcionalidade, usabilidade, segurança, estética, qualidade, durabilidade, manufaturabilidade, ergonomia e viabilidade técnica que formam o sistema do PDP e fundamenta-se o que passa a ser chamado ecodesign (PLATCHECK, 2012).

Há cinco níveis de intervenção possíveis neste "sistema": minimização de recursos com redução do uso de materiais e de energia; escolha de recursos e de processos de baixo impacto ambiental, selecionando materiais, processos e fontes energéticas de maior ecocompatibilidade; otimização da vida dos produtos, ao projetar artefatos que perdurem; extensão da vida dos materiais, ao projetar em função da valorização dos materiais (reaplicação); e, facilidade de desmontagem (MANZINI e VEZZOLI, 2011). Essas diretrizes metodológicas estabelecem os pressupostos para o desenvolvimento de produtos sustentáveis, tipicamente caracterizados como bens associados às matérias-primas naturais e orgânicas ou àquelas de alta tecnologia produzidas a partir de matérias recicladas, manufaturados em processos não poluentes e de baixo impacto ambiental (FLETCHER e GROSE, 2011). Cada vez mais, a essas características associam-se questões sociais, tanto no tocante aos impactos causados pelos meios produtivos da indústria (mão de obra, comércio justo, etc.), quanto aos esforços isolados para promover o desenvolvimento social (id., 2011).

O desenvolvimento de produtos de moda sustentáveis demanda um ajuste das operações existentes e, por meio de atividades responsáveis e inovação tecnológica, sugere a introdução de bens e serviços menos poluentes e com senso de 
interconectividade para todos os envolvidos na cadeia de valor (FLETCHER e GROSE, 2011; BIRKELAND, 2002).

\section{Empresas de Fast Fashion}

Desde que a indústria da moda se organizou internacionalmente no final dos anos de 1940, o setor se movimenta em torno de um sistema de produção estável e pronto para ser replicado, chamado pronto-para-usar, que é revisto a cada nova estação, quando as coleções de produtos são substituídas por novos itens com outras características capazes de acompanhar as mudanças no lifestyle e nos desejos de consumo (LIPOVETSKY, 1989).

Em função das mudanças no ambiente de negócios, algumas empresas de moda passam a investir na velocidade para o mercado e oferecem tendências de moda assim que são reveladas nas principais semanas de moda do mundo (BHARDWAJ e FAIRHURST, 2010). Este modelo de operação chamado "fast fashion" (moda rápida) acelerou a competitividade, pois encurtou o processo de oferta das novidades. Desde os últimos anos do século $\mathrm{XX}$, esse titulo faz referência à baixa previsibilidade, ciclo de vida curto e demanda de mercado altamente volátil (CIETTA, 2010; FERNIE e AZUMA, 2004).

A caracterização das empresas de moda por meio de suas capacidades de resposta ao mercado e da importância do grupo de pares em seus projetos é elucidada na tipologia empresarial apresentada na figura 3 (FERNIE e AZUMA, 2004). 
Figura 3: Tipologia das empresas de design de moda

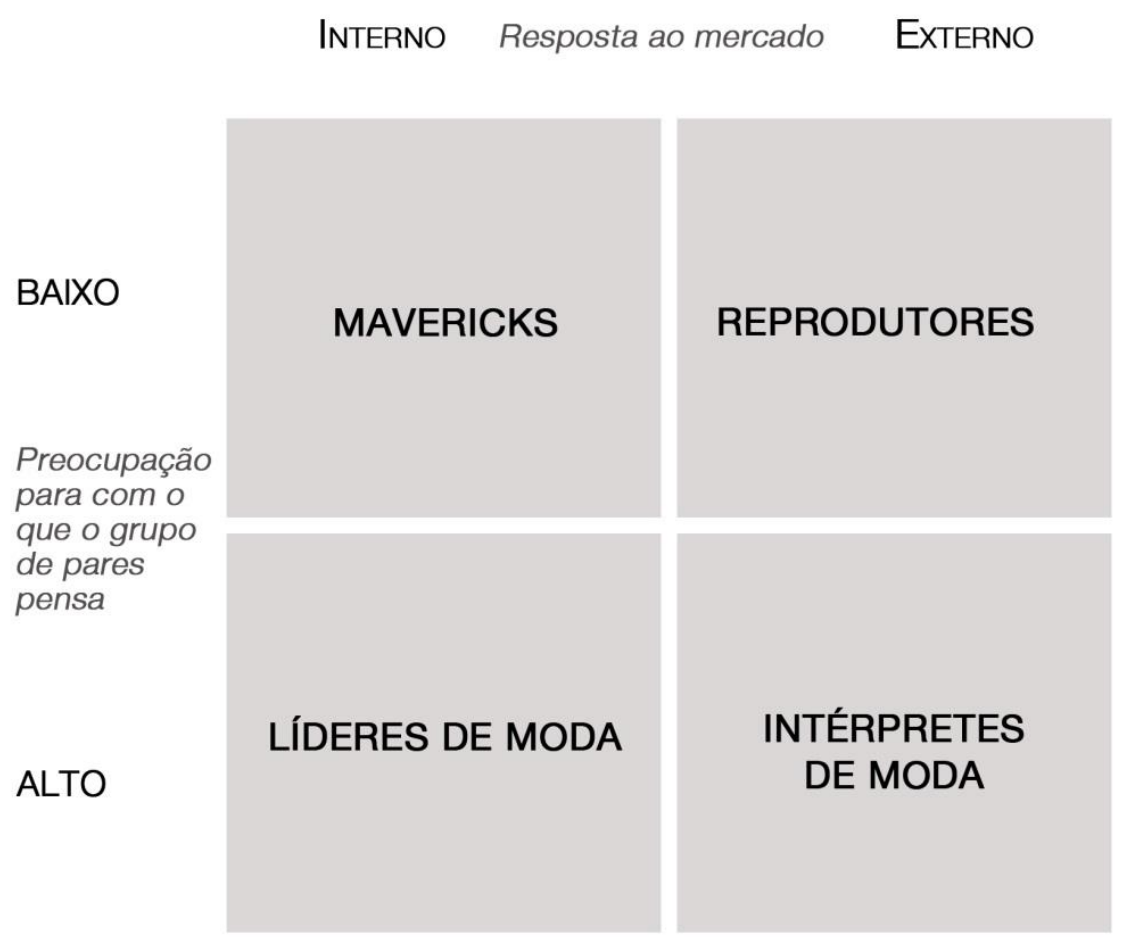

Caracterização das empresas de moda por meio de suas capacidades de resposta ao mercado. Fonte:

Fernie e Azuma, 2004

'Mavericks' não se preocupam em ser parte daquilo que seus consumidores pensam; têm pequena participação de mercado e oferecem produtos de moda autoral. Os 'Reprodutores' identificam um grupo de clientes-alvo e produzem, de maneira regular e estável, produtos que podem ser imitação de outros. 'Líderes de moda' são empresas guiadas pelo design diferenciado, com forte posicionamento de marca, geralmente apontadas como formadoras de opinião e de novas tendências. Os 'Intérpretes de Moda' são as empresas preocupadas em produzir roupas que 'estão na moda' e oferecem a 'moda rápida'. Em função disso, interessam-se pelo que a concorrência faz, disponibilizando rapidamente no mercado produtos que ganharam destaque em desfiles de moda, revistas ou programas de TV. Os 'Intérpretes' 
demonstram alta preocupação sobre o que o grupo de pares pensa, configuram suas operações considerando a organização de sua cadeia produtiva e alcançam alta resposta no mercado (RIEPLE e GANDER, 2009).

\section{MÉTODO DE PESQUISA}

Este estudo é caracterizado como uma pesquisa qualitativa, do ponto de vista da abordagem, e descritivo exploratório, no tocante aos seus objetivos, visando proporcionar maior familiaridade com os problemas, ao descrevê-los completamente (YIN, 2005). Considerando o contexto em que o fenômeno da pesquisa se desenvolve, opta-se pela estratégia do método de estudo de casos múltiplos, que representa uma maneira de investigar um tópico empírico em casos relacionados pelo tempo e pela atividade (id., 2005).

O estudo de casos múltiplos, tipicamente, provém de uma base robusta e consistente para a construção de teoria, enquanto a revisão de literatura ampara a observação e explica algumas propriedades comuns aos casos (EISENHARDT, 1989).

A estratégia se inicia com um projeto de pesquisa que define questões do estudo e respectivas proposições, unidades de análise e a lógica e critérios usados para interpretar os dados (YIN, 2005), explicitados no Quadro 1. 
Quadro 1: Projeto de pesquisa do estudo de casos múltiplos

\begin{tabular}{|c|c|}
\hline $\begin{array}{c}\text { COMPONENTE DO } \\
\text { PRONETO }\end{array}$ & ESPECIFICACCĀO NA PESQUISA \\
\hline Questōes do Estudo & $\begin{array}{l}\text { Caracterizaçāo e gestão socioambiental de empresas brasileiras de } \\
\text { varejo de moda de médio porte; motivadores e barreiras para o } \\
\text { desenvolvimento de produtos sustentáveis e de que modo podem criar } \\
\text { valor. }\end{array}$ \\
\hline Proposiçāo & $\begin{array}{l}\text { A criaçāo de valor com o desenvolvimento de produtos de moda } \\
\text { sustentáveis está ancorada em capacidades estratégicas aplicadas em } \\
\text { padrōes e processos responsáveis pelos quais as empresas } \\
\text { desempenham atividades intemas e pelo modo sustentável como se } \\
\text { relacionam e interagem com seus stakeholders. }\end{array}$ \\
\hline Unidades de Análise & As empresas, a visāo dos gestores e os PDPs. \\
\hline $\begin{array}{l}\text { Lógica e Critérios para } \\
\text { Interpretar as } \\
\text { Constataçōes }\end{array}$ & $\begin{array}{l}\text { As informaçōes sāo descritas em cada caso para que, a partir de um } \\
\text { corte epistemológico por meio de categorias de análise, o cruzamento } \\
\text { dos dados é realizado. }\end{array}$ \\
\hline
\end{tabular}

Componentes e especificações deste estudo. Fonte: Yin (2004) adaptado pelos autores (2013).

Este método é amparado pelo protocolo do estudo de caso, que traça uma visão geral do estudo, potenciais fontes de informação para responder as questões centrais, procedimentos de campo e um guia para o relatório dos casos (YIN, 2005).

A seleção de casos objetiva a expansão da teoria emergente e, por uma razão teórica, se restringe a empresas de porte médio [caracterizado pelo faturamento - entre R\$ 90 milhões e R\$ 300 milhões - e número de funcionários - entre 100 e 499 empregados (BNDES, 2011)] do setor de confecção e varejo de moda, localizadas no Estado do Rio de Janeiro e que operam no modelo fast fashion.

A coleta de dados para um estudo de caso deve ser proveniente de diferentes fontes (EISENHARDT, 1989; YIN, 2005). Neste estudo, utilizam-se entrevistas, observações diretas e análise de documentos.

Com base nos conceitos teóricos elucidados pela revisão de literatura, dois roteiros com perguntas semiestruturadas conduziram entrevistas com diretores executivos e diretores de criação de produtos. Os roteiros foram revisados após a condução do caso piloto. O primeiro roteiro investigou perfil da empresa, modelo de gestão, comprometimento com a sustentabilidade e ferramentas para criação de valor; o segundo abordou temas específicos do PDP, como rotina de atividades e os mecanismos 
indutores e principais entraves para o desenvolvimento de produtos de moda sustentável. Para as observações diretas, foram realizadas visitas formais às empresas e a seus pontos de venda, onde se pôde observar o ambiente e aspectos relacionados aos produtos.

O estudo dos casos se inicia com a elaboração de padrões para a interpretação cruzada das informações: cada caso é identificado pela inicial ' $E$ ' de empresa, seguido das letras A, B, C e D. Os casos são descritos separadamente, a fim de evidenciar características organizacionais e particularidades da gestão empresarial, processos para o desenvolvimento de produtos e percepção sobre pontos de alavancagem e entraves para a criação de roupas e acessórios limpos. Por fim, estuda-se as capacidades para gerar valor sustentável por meio de estratégias propostas no modelo de Hart e Milstein (2004). Em seguida, procuram-se semelhanças e diferenças intergrupais e realiza-se a síntese de casos cruzados (EISENHARDT, 1989) a partir das dimensões gerais do estudo - gestão socioambiental, criação de valor e desenvolvimento de produtos de moda - e da codificação de sete categorias correspondentes (tipologia das empresas; visão dos gestores; caracterização dos produtos; fluxo das atividades de PDP; mecanismos indutores e entraves para práticas responsáveis no PDP; e, estratégias de criação de valor sustentável).

O protocolo do estudo e o banco de dados sobre os casos sugerem a confiabilidade qualitativa da pesquisa (YIN, 2005), que tem sua validade garantida pela provisão de descrições densas e detalhadas que firmem uma sólida estrutura para comparação dos casos (EISENHARDT, 1989).

\section{Estudo dos Casos}

Esta seção apresenta os resultados dos quatro estudos de caso realizados.

\section{EMPRESA A}

A Empresa A (E_A) iniciou sua trajetória no varejo de moda carioca em 1996 com a criação de um negócio familiar, em que os dois sócios tinham igualdade de cotas. O negócio tornou-se uma operação de rede que gera 500 empregos diretos - e cerca de 1500 indiretos -, soma 24 lojas próprias e cerca de 700 pontos de venda no Brasil. A empresa tem uma unidade fabril, onde confecciona $40 \%$ do total de 1,1 milhão de peças 
comercializadas por ano.

O posicionamento da marca é associado à ampla oferta de produtos - em torno de 700 itens lançados a cada estação. O sistema do PDP é baseado nas tendências de moda que definem novos materiais, formas, cores ou estamparia exclusivos. Esses produtos atualizados e a manutenção do conceito de uma marca jovem e sensual com foco na classe B guardam, segundo o diretor criativo, a principal vantagem competitiva da empresa.

Para o diretor executivo, as políticas governamentais e os encargos fiscais impedem investimentos em todos os setores da firma. A empresa afirma desconhecer as diretrizes para práticas de gestão socioambiental e mostra-se empenhada na redução de custos com foco no aumento da rentabilidade e na tentativa de originar um produto com preço final mais acessível para o consumidor. Contudo, algumas ações responsáveis são detectadas nas práticas da empresa, como, por exemplo, no direito das relações de trabalho e no engajamento com a cadeia de suprimentos que, segundo o diretor criativo, cria possibilidades de desenvolvimento para ambas as partes.

E_A aponta para o próprio modelo de negócio da firma, que comercializa um produto feito para ser descartado, como um dos entraves para o desenvolvimento de produtos sustentáveis. A isso, o diretor executivo soma a dificuldade financeira para investimentos de longo prazo e alega que todas as ações responsáveis impactam no preço final dos produtos. A diretora de criação afirma que a entrada de um parceiro com knowhow sobre diretrizes da RSE e com prática em ecoeficiência motivaria o desenvolvimento de produtos mais limpos, além de incentivos fiscais e controle governamental.

O diagnóstico das capacidades estratégicas da E_A mostra, discretamente e sem sistematização, força emergente em práticas de controle de poluição - com redução de resíduos têxteis e otimização de transporte de mercadorias - e força não existente no manejo de produtos. Internamente, esta observação sugere que a empresa tende a ficar vulnerável no futuro porque não se prepara tecnicamente com a aplicação de tecnologia limpa em suas operações. Externamente, a análise aponta para a falta de habilidade operacional ou analítica, que impulsiona a implementação de uma visão integrada e sustentável para o negócio. 


\section{Empresa B}

Há seis anos no mercado, a Empresa B (E_B) tem seis lojas próprias e 50 franqueadas que comercializam cerca de 300 mil peças/ano. O negócio familiar com dois sócios é focado no consumidor da Classe C, emprega 250 funcionários (gera cerca de 900 empregos indiretos) e aposta em produtos que são febre de moda. Segundo o diretor executivo, a firma é regida pela lógica da gestão de produtos, ou seja, todas as decisões estratégicas são tomadas em função da otimização da melhoria de preço, acesso a materiais, tecnologias de produção etc, a fim de criar valor e diferencial competitivo com as roupas e acessórios que atendam ao gosto da massa.

E_B possui um centro de desenvolvimento e prototipagem de produtos confeccionados por facções brasileiras ou fabricados por firmas chinesas, o que, de acordo com a diretora de criação, possibilita melhorar o sortimento, com mais qualidade e melhor preço do que o obtido com produção interna nacional.

E_B empenha-se na consolidação do modelo de negócio, com o intuito de fortalecer a marca e vendê-la posteriormente, explica o diretor executivo. Com isso, apesar da direção não identificar condutas responsáveis nas atividades da empresa, algumas atividades relacionadas à gestão socioambiental acabam sendo realizadas, como, por exemplo: desenvolvimento e aproveitamento de mão de obra local em atividades operacionais, privilegiando a geração de renda para comunidades que vivem na região Serrana do Estado do Rio de Janeiro, investimento em tecnologia de ponta que elimina a geração de resíduo têxtil na fase do corte de tecidos $(40 \%$ dos produtos feitos em facções contratadas são cortados na sede da empresa), ou uso de rotas de transporte de mercadorias que minimiza a emissão de gases.

Para o diretor executivo, o consumidor é o principal entrave e o primeiro motivador para o desenvolvimento de produtos sustentáveis. "Se o consumidor não valoriza, ele não paga mais pelo produto, e as empresas de moda não podem correr esse risco", avalia. A diretora de criação aponta a cadeia de suprimentos desorganizada como uma barreira pela falta de controle de práticas e processos. Ela destaca a dificuldade para firmar parcerias com comunidades de manejo sustentável ou com associações de artesãs. Além do incentivo fiscal e controle governamental, ambos diretores dizem que a mudança na cadeia de valor da moda seria um motivador para a implantação de produtos limpos, pois todos se organizarão para atuar com os mesmos valores e 
parâmetros.

O diagnóstico das capacidades estratégicas da E_B demonstra estratégias de manejo de produtos com forças estabelecidas, sobretudo, nas relações com stakeholders e na transparência da gestão. Na visão de sustentabilidade, a estratégia se mostra como força emergente uma vez que a direção investe em processos de desenvolvimento que fortaleçam a firma. Internamente, como sua produção de resíduos é mínima, as ações ecoeficientes se concentram na otimização logística de transportes e materiais de embalagens demonstrando uma força emergente em ações que podem ser ampliadas para outras dimensões do produto. Ações de tecnologia limpa indicam força emergente notadas no desenvolvimento de ecoeficácia - com investimento em maquinário de prototipagem e corte de tecidos - e em processos de gestão com conhecimento compartilhado - uso do software Totvs - e transparência de informações - ao recusar parcerias de marketing verde.

\section{Empresa C}

Fundada em 1982, o negócio familiar da Empresa C (E_C) ocupa dois prédios em São Cristóvão, no Rio de janeiro. Formada por três sócios, gera cerca de 450 postos de trabalho diretos e possui 17 lojas próprias. Cerca de 600 mil produtos são vendidos por ano em uma rede comercial que inclui 600 multimarcas brasileiras.

Segundo o diretor executivo, seu modelo de negócio é baseado na sobrevivência, ou seja, sua atuação no mercado é adequada para manter-se competitivo. Ele destaca a habilidade para observar e analisar o mercado e dialogar com stakeholders como capacidades para adequação da operação.

Sem identidade definida, a marca é associada à vastidão de estilos presentes no sortimento de 500 produtos a cada nova estação. Conforme explica a diretora criativa, as peças são desenvolvidas com base em tendências estético-formais observadas na concorrência e interpretadas pela ideia de que os produtos devem atender às ansiedades de uma consumidora jovem e sensual, vaidosa com o corpo e adepta de ornamentos. $\mathrm{O}$ PDP se divide entre a criação feita por uma equipe interna e a gestão de produtos terceirizados, e conta com $10 \%$ de produtos importados da China.

E_C desconhece diretrizes para gestão socioambiental e, de acordo com o diretor executivo, a conduta ética e a prática de eventuais atividades filantrópicas é o máximo que uma empresa de moda brasileira atuante no varejo de médio porte consegue fazer. 
Ele assegura que a reorganização do setor impacta as atividades do seu negócio, pois demanda máxima atenção aos ajustes de processos fabris - para acompanhar a velocidade dos lançamentos a cada três meses - e incorporação de custos derivados do processo em andamento da legalização das atividades em todas as pontas da cadeia produtiva.

E_C indica três barreiras para o desenvolvimento de produtos sustentáveis: falta de conhecimento sobre processos e materiais, cadeia produtiva fracionada, aumento do preço final do produto oriundo da melhoria das práticas. Segundo a diretora criativa, os pontos de alavancagem para desenvolvimento de produtos sustentáveis são a tendência de moda de produtos limpos e a divulgação de materiais responsáveis por parte de tecelagens. O diretor executivo diz que as práticas responsáveis seriam motivadas por maior participação no mercado e incentivos fiscais.

As atividades da E_C estão concentradas em soluções do presente. O diagnóstico das capacidades estratégicas demonstra forças não existentes nas ações internas com foco no futuro e também nas práticas externas que envolvem o manejo de produtos. Há poucas medidas emergentes alavancadas por atividades não programadas de controle de poluição e não existe estratégia de tecnologia limpa. A firma não demonstra potencial para realizar melhorias, seja por meio de escolhas disruptivas ou através de suporte tecnológico que empreenda novas configurações a processos de gestão ou desenvolvimento de produtos e aos bens comercializados. A visão de sustentabilidade é uma estratégia com força emergente em atividades como compartilhamento de informações com foco no desenvolvimento do setor, geração de emprego e fortalecimento da rede de colaboradores e apoio a instituições beneficentes e ONGs.

\section{Empresa D}

A Empresa D (E_D), fundada em 1997, é um negócio familiar de dois sócios com igualdade de cotas. Possui 450 funcionários, 29 lojas próprias, 32 franquias e 500 pontos de venda em multimarcas. Tem cerca de um milhão de produtos comercializados/ano destinados à consumidora de classe media alta e, segundo a diretora de criação, caracterizados como atual, artesanal, detalhado e romântico. 
Para o diretor executivo, o produto norteia o modelo de gestão, baseado na ótica de valores femininos e não no preço, como os demais players do setor. Ele destaca a capacidade de oferecer produtos com características tangíveis e intangíveis, valorizadas pela consumidora, permitindo a construção de uma visão ampliada do negócio ao interagir com stakeholders (fornecedores de insumos, franqueados e representantes comerciais, parceiros de co-branding). Ele afirma que revê anualmente o plano estratégico.

Com identidade de produtos bem definida, E_D divide o PDP em dois modelos de atividades: a prototipagem e o corte das peças, que podem ser realizados na sede da empresa. Também há possibilidade de serem executados por uma firma terceirizada, que manuseia os insumos desde a prototipagem até a produção.

Em 2013, E_D iniciou os procedimentos para implantação de uma gestão socioambiental (embora não seja intitulada deste modo por seus diretores) a partir de medidas como a transmissão de valores construídos com operações transparentes nas atividades desenvolvidas interna e externamente. Para isso, criou um departamento de qualidade que sistematiza o código de conduta e estabelece parâmetros dos processos e produtos de toda a empresa.

Segundo o diretor executivo, as principais barreiras para o desenvolvimento de produtos sustentáveis estão atreladas às dificuldades na manutenção prática do negócio de moda, a baixa margem financeira, a concorrência acirrada, a disponibilidade de capital próprio, o cumprimento de atividades fiscais e a inconstância do mercado. E_D credita ao conhecimento mais claro sobre as vantagens que as atividades responsáveis trarão aos negócios o principal ponto de alavancagem para o desenvolvimento de produtos sustentáveis, que ainda podem ser motivados por acesso a recursos, parcerias com o setor têxtil, incentivo fiscal e o controle governamental.

Observa-se no conjunto de capacidades estratégicas de E_D forças estabelecidas nas atividades de prevenção de poluição e manejo de produtos. A firma traça estratégias em torno das atividades do recém-criado departamento de qualidade que, entre outras iniciativas, prevê ações que reduzam custos, riscos e impactos ambientais, atuando, por exemplo, na minimização de resíduos têxteis e no cuidado com emissão de gases no transporte de mercadorias. Sobre o manejo de produtos, a empresa estabeleceu uma estratégia, investindo na relação transparente com integrantes da cadeia produtiva, 
buscando agregar visões e interesses nas atividades desenvolvidas, além de destacar a importância da análise e o controle do ciclo de vida dos produtos. O diretor executivo afirma que esse tipo de ação só é possível com verticalização das atividades, cujo risco é alto e incabível para empresas que não focam em escala mas em diferenciação.

E_D reconhece que a estratégia de tecnologia limpa é uma força não existente, pois este não é um tema considerado de modo claro nas decisões sobre alocação de recursos ou seleção de técnicas e processos nas diversas atividades da firma. A estratégia de visão de sustentabilidade é uma força que se mostra emergente, conduzida pela preocupação com o bem-estar dos que sofrem impacto das atividades lucrativas e sustentáveis da firma.

\section{SÍNTESE DOS CASOS CRUZADOS}

Nesta seção, os dados coletados são explorados sob o prisma da caracterização das empresas do setor e suas principais práticas de PDP; em seguida, examinam-se as atividades empresariais gerais que atendem as diretrizes de gestão socioambiental, com ênfase nos mecanismos indutores para desenvolvimento de produtos sustentáveis. Por fim, são avaliadas as estratégias adotadas pelas empresas com potencial para criar valor.

\section{As empresas e suas práticas de PDP}

As empresas estudadas são familiares, dedicadas à confecção e comercialização de produtos de moda, com operação caracterizada pelo fast fashion adaptado, porque algumas características essenciais foram adequadas para atender as demandas dos sistemas de franquia e atacado, conforme listado no Quadro 2. 
Quadro 2: Fast fashion adaptado

\begin{tabular}{|l|l|l|}
\hline \multicolumn{1}{|c|}{$\begin{array}{c}\text { CARACTERISTICA } \\
\text { FAST FASHION }\end{array}$} & \multicolumn{1}{|c|}{$\begin{array}{c}\text { CARACTERISTICA } \\
\text { ORIGINAL }\end{array}$} & \multicolumn{1}{|c|}{$\begin{array}{c}\text { CARACTERISTICA } \\
\text { ADAPTADA }\end{array}$} \\
\hline $\begin{array}{l}\text { Prazo para desenvolvimento } \\
\text { de produtos }\end{array}$ & $\begin{array}{l}\text { Agilidade entre concepção e } \\
\text { entrega do produto com prazos de } \\
45 \text { dias em média. }\end{array}$ & $\begin{array}{l}\text { Sem agīidade da operaçāo } \\
\text { fabril e com a necessidade de } \\
\text { prazo para pedidos do } \\
\text { atacado, olead time varia de } \\
6 \text { a 8 meses. }\end{array}$ \\
\hline $\begin{array}{l}\text { Atividades Orientadas para } \\
\text { o mercado }\end{array}$ & $\begin{array}{l}\text { Oferece tendências lançadas em } \\
\text { semanas de moda e divulgadas } \\
\text { pelos grandes media. }\end{array}$ & $\begin{array}{l}\text { Oferece tendências } \\
\text { 'atrasadas' e febres de moda } \\
\text { promovidas por redes } \\
\text { midiáticas locais. }\end{array}$ \\
\hline $\begin{array}{l}\text { Equipe de desenvolvimento } \\
\text { de produtos }\end{array}$ & $\begin{array}{l}\text { Enorme quantidade de profissionais } \\
\text { em atividades especializadas. }\end{array}$ & $\begin{array}{l}\text { Equipes reduzidas com } \\
\text { profissionais em multifunçōes. }\end{array}$ \\
\hline
\end{tabular}

Especificações das principais adaptações do modelo fast fashion. Fonte: BHARDWAJ e FAIRHURST (2010) e Cietta (2010) adaptado pelos autores (2013).

Para as empresas, a adaptação do modelo fast fashion e a adequação de produtos as tornam 'intérpretes de moda', à exceção da E_B, que se assume 'reprodutora de moda'. Todavia, apenas E_A é do tipo "Intérprete de moda”, pois E_B oferece produtos já em fase de maturação no mercado, enquanto E_C não possui agilidade para lançar minicoleções com novidades e E_D foca em um nicho de mercado, produzindo, de maneira regular, artigos que não são necessariamente tendências de moda, o que as tipifica como 'reprodutoras' (RIEPLE e GANDER, 2009).

As empresas apresentam forte dependência em alguns elos da cadeia produtiva, como o acesso a insumos têxteis, e interdependência no conjunto de atividades que movimenta o setor, em função das atividades poucos sistematizadas de meios de produção. Todas as empresas realizam as quatro fases comportadas no processo clássico de PDP. Contudo, com produtos diferenciados por estética e preço, apresentam particularidades na gestão de compras, sortimento e no tocante às técnicas e meios de criação, à produção e velocidade de entrega ao mercado. Tais particularidades estão principalmente associadas às características dos produtos, à capacidade de assimilar mudanças e tendências de mercado e ao modelo de produção. Nenhuma das empresas incorpora os pressupostos de ecodesign em seus sistemas de PDP e tampouco se 
mostram envolvidas com alguma interferência no sistema produtivo que vise à redução do impacto ambiental.

\section{Práticas empresariais e a gestão socioambiental}

As empresas estudadas desconhecem diretrizes para práticas responsáveis, à exceção da E_B, e a visão dos gestores evidencia que este tema não é difundido entre seus públicos de relacionamento. As práticas são movidas pelas necessidades imediatas do mercado. Apenas E_D possui um plano estratégico de gestão implantado. Na visão dos diretores, a gestão socioambiental, conduzida por diretrizes e normas, é custosa e depende de profissionais especializados. Apesar de não sistematizarem práticas socioambientais responsáveis, E_B, E_C e E_D afirmam que a conduta da organização deve ser coerente com as propostas do negócio e dão evidências de que entendem que o compromisso social é uma dimensão de atuação não apenas dos gestores, mas de todos os que fazem parte da empresa. As três companhias dizem que os empresários precisam ser convencidos das vantagens desse compromisso para seus negócios.

\section{Mecanismos indutores para desenvolvimento de produtos sustentáveis}

As empresas apontam motivadores internos e externos para melhores práticas no sistema de PDP, conforme listado no Quadro 3. Porém, não há evidências de que assumam estratégica e operacionalmente algum dos motivadores listados. 
Quadro 3: Mecanismos indutores para o desenvolvimento de produtos sustentáveis

\begin{tabular}{|c|c|}
\hline 1. Demanda do consumidor & 7. Qualidade e ecoeficiência de fabricantes \\
\hline 2. Produto sustentável deve estar na moda & 8. Investimento financeiro de parceiro externo \\
\hline 3. Ampliaçāo de participação no mercado & $\begin{array}{l}\text { 9. Acesso a conhecimento sobre diretrizes de } \\
\text { RSE }\end{array}$ \\
\hline $\begin{array}{l}\text { 4. Construçāo de uma cultura organizacional que } \\
\text { valorize pessoas }\end{array}$ & 10. Incentivo fiscal \\
\hline 5. Divulgaçāo de insumos sustentáveis & 11. Controle do Governo \\
\hline 6. Acesso a materiais sustentáveis & $\begin{array}{l}\text { 12. Criaçāo de vantagem competitiva frente à } \\
\text { concorrência }\end{array}$ \\
\hline
\end{tabular}

Motivadores para o desenvolvimento de produtos sustentáveis na visão dos gestores. Fonte: Alves e Dalto (2013).

\section{Entraves para desenvolvimento de produtos sustentáveis}

As empresas associam os produtos sustentáveis ao aumento de custos e à falta de demanda do consumidor, apontadas entre outras dez barreiras ao desenvolvimento de produtos limpos, conforme listadas no Quadro 4. 
Quadro 4: Entraves para o desenvolvimento de produtos sustentáveis

\begin{tabular}{|c|c|}
\hline $\begin{array}{l}\text { 1. Limitaçâo de capital próprio para investimento } \\
\text { em processos e produtos com baixo retorno } \\
\text { imediato }\end{array}$ & $\begin{array}{l}\text { 7. Falta de preparo profissional, técnico e de } \\
\text { gestāo }\end{array}$ \\
\hline $\begin{array}{l}\text { 2. Dificuldade para mensurar o retorno sobre } \\
\text { investimento }\end{array}$ & $\begin{array}{l}\text { 8. Ausência de departamento ou profissional } \\
\text { dedicado a RSE }\end{array}$ \\
\hline 3. Cadeia produtiva pouco organizada & 9. Custo alto de processos e insumos \\
\hline $\begin{array}{l}\text { 4. Modelo de negócio que se mantém com } \\
\text { produto para ser descartado }\end{array}$ & $\begin{array}{l}\text { 10. Falta de motivaçāo para a equipe de } \\
\text { designers assumir parâmetros sustentáveis em } \\
\text { seus projetos }\end{array}$ \\
\hline $\begin{array}{l}\text { 5. Falta de compartilhamento de informaçōes } \\
\text { entre integrantes da cadeia produtiva }\end{array}$ & $\begin{array}{l}\text { 11. Falta de capacidade/dificuldades para firmar } \\
\text { parcerias sistematizadas com ONGs e outras } \\
\text { organizaçōes }\end{array}$ \\
\hline $\begin{array}{l}\text { 6. Falta de conhecimento e controle sobre } \\
\text { praticas de fornecedores }\end{array}$ & $\begin{array}{l}\text { 12. Consumidor nāo valoriza produtos com } \\
\text { caracteristicas sustentáveis }\end{array}$ \\
\hline
\end{tabular}

Barreiras para o desenvolvimento de produtos sustentáveis na visão dos gestores. Fonte: Alves e Dalto (2013).

\section{Forças para criar valor com produtos sustentáveis}

De acordo com o modelo de diagnóstico de atividades de valor sustentável (HART, 1997) as empresas têm suas capacidades caracterizadas da seguinte maneira:

1. Internamente, na estratégia de prevenção de poluição, mostram forças emergentes, porém, não sistematizadas, e apenas E-D demonstra força estabelecida em função da criação de um departamento de qualidade; na estratégia de tecnologia limpa há evidências de forças não existentes, à exceção de E_B, que investe na minimização de resíduos que causam impactos ambientais com foco na redução de custos.

2. Externamente, por meio da estratégia de manejo de produtos, E_B e E_D mostram forças estabelecidas especificamente em função da visão dos gestores, que identificam a necessidade de investimento na relação com os integrantes da cadeia produtiva, enquanto nas demais tal força é não existente. No tocante à visão de sustentabilidade, a falta de habilidade operacional ou analítica que impulsione a implementação de visão integrada para o negócio não proporciona forças para um posicionamento diferenciado no futuro. Contudo, atividades não planejadas para a sustentabilidade são identificadas como possíveis forças emergentes, entre elas, por 
exemplo, o compartilhamento de informações com foco no desenvolvimento do setor, geração de emprego no entorno de suas operações, desenvolvimento da rede de colaboradores e apoio a instituições beneficentes e ONGs.

\section{Considerações Finais}

Este estudo permitiu caracterizar empresas brasileiras de varejo de moda de médio porte no tocante às ações e iniciativas socioambientais, mostrando que possuem uma visão que não integra os domínios econômico, ético e legal, que desconfiam do retorno financeiro proveniente de atividades responsáveis, enquanto se dedicam a profissionalizar as atividades e a consolidar o processo de formalização do negócio, atuando de modo reativo e investindo em processos, equipamentos, sistemas ou produtos que estão na moda.

Especificamente sobre as ações socioambientais, a pesquisa observa que as empresas desconhecem diretrizes de gestão socioambiental ou RSE, investem em processos que minimizam custos diretos e imediatos e desconsideram parâmetros socioambientais no processo de desenvolvimento de produtos.

Evidenciou-se que os principais pontos de alavancagem para o desenvolvimento roupas e acessórios sustentáveis no Brasil estão atrelados ao acesso a informações técnicas e tecnológicas sobre procedimentos, processos e materiais, e diretrizes socioambientais aplicáveis à gestão de produto -, investimento dos integrantes da cadeia produtiva em qualidade e ecoeficiência, incentivo fiscal e o desejo do consumidor manifesto como tendência de moda sustentável.

Os principais entraves para o desenvolvimento de produtos sustentáveis no varejo de moda brasileiro são evidenciados na própria cadeia produtiva, que se revela desorganizada, sem controle, sem conhecimento sobre a relevância e vantagens de práticas socioambientais e o desprezo do consumidor por produtos com tais características. Além disso, aparecem também as barreiras internas associadas à limitação de capital próprio para investimento em processos e produtos com baixo retorno imediato, dificuldades para mensurar o retorno do investimento e a falta de capacidade para firmar parcerias.

A pesquisa elucida dados que demonstram que as empresas do setor varejista de 
moda podem contribuir para o desenvolvimento sustentável e gerar valor em suas cadeias produtivas por meio de algumas ações, tais como legalizar as atividades e participar de modo mais responsável nas operações de mercado que as mantêm financeiramente rentáveis, gerar emprego e renda, promovendo o desenvolvimento humano em uma sociedade inclusiva e responsável, sistematizar processos em prol de qualidade e ecoeficiência, capacitando-se para a criação de valor ambiental, social e financeiro, definir código de conduta com fornecedores, desenvolvendo uma relação transparente, conectada e justa, e investir em equipamentos diferenciados para atividades fabris, que devem passar a considerar a opção de materiais sustentáveis e processos limpos de beneficiamento dos produtos com vistas para a redução do impacto ambiental.

O desenvolvimento de produtos sustentáveis pode, portanto, criar valor em empresas brasileiras de varejo de moda com a adoção de práticas responsáveis proativas que desmaterializam objetos em um processo que inclui, além dos ajustes formalmaterial, os domínios econômico, ético e legal na promoção dos critérios de desenvolvimento sustentável em todas as atividades do sistema da moda. Entende-se que os resultados contribuem para a criação de uma efetiva agenda verde para o varejo de médio porte, com destaque para as atividades de manejo de produtos, promovendo a importância da incorporação de ferramentas e práticas de gestão que criem valor e melhorem as relações das empresas com o planeta e com a sociedade.

Artigo recebido em Outubro de 2015. Aprovado em Maio de 2016

DOI:http://dx.doi.org/105965/1982615×09182016305

\section{REFERÊNCIAS}

ABIT. Agenda de Prioridades Têxtil e de Confecção - 2015/2018. Associação Brasileira da Indústria Têxtil e de Confecção, São Paulo, p. 35, Cap 1, 2014. 
ABIT. Perfil do setor têxtil e de confecção em 2014. Programa de Internacionalização da Indústria da Moda Brasileira, São Paulo, 2015. Versão digital disponível em: http://www.texbrasil.com.br/Texbrasil/TexBrasil.aspx?tipo=1\&pag=1\&nav=0\&tela=SO BRE\%20O\%20TEXBRASIL\&.

BARBIERI, J.C.; CAJAZEIRA, J. E. Responsabilidade social empresarial e empresa sustentável: da teoria à prática. São Paulo: Saraiva, 2012.

BARNEY, J. Firm Resources and Sustained Competitive Advantage. Journal of Management, v. 17, n. 1, p. 99-120, 1991.

BHARDWAJ, V.; FAIRHURST, A. Fast Fashion: Response to Changes in the Fashion Industry. The International Review of Retail, Distribution and Consumer Research, v. 20, n. 1, p. 165-173, 2010.

BIRKELAND, J. Design For Sustainability: A Sourcebook of Integrated Ecological Solutions. London: Earthscan, 2002.

BNDES. Circular Interna Referente ao Porte das Empresas. Banco Nacional de Desenvolvimento, $2010 . \quad$ Disponível em http://www.bndes.gov.br/SiteBNDES/export/sites/default/bndes_pt/Galerias/Arquivos/p rodutos/download/Circ011_10.pdf. Acesso em 10/01/2013.

CIETTA, E. A Revolução do Fast Fashion: estratégias e modelos organizativos para competir em indústrias híbridas. São Paulo: Editora Estação das Letras e Cores, 2010.

DAHER, W., OLIVEIRA, M., CALS, B., e PONTE, V. Responsabilidade Social Corporativa Segundo o Modelo de Hopkins: Um Estudo nas Empresas do Setor Energético do Nordeste Brasileiro. Revista de Gestão Social e Ambiental, 1(1), p. 3146, 2007.

EISENHARDT, K. Building Theories from Case Study Research. Academy of Management Review, v. 14, n. 4, p. 532-550, 1989.

ELKINGTON, J. Canibais com Garfo e Faca. São Paulo: Makron, 2001.

ETHOS. Processos Gerenciais: Responsabilidade Social Empresarial. São Paulo: Instituto Ethos, 2007. 
FERNIE, J.; AZUMA, N. The Changing Nature of Japanese Fashion: Can Quick Response Improve Supply Chain Efficiency? European Journal of Marketing, v. 38, n. 7, p. 749-69, 2004.

FIKSEL, J. Achieving Eco-efficiency Through Design for Environment. Environmental Quality Management, v. 5, n. 4, p. 47-54, 1996.

FLETCHER, K; GROSE, L.. Moda e Sustentabilidade: design para mudança. São Paulo: Editora SENAC São Paulo, 2011.

HART, S. O Capitalismo na Encruzilhada: as inúmeras oportunidades de negócios na solução dos problemas mais difíceis do mundo. Porto Alegre: Bookman, 2006.

HART, S.; MILSTEIN, M. Criando Valor Sustentável. Revista de Administração de Empresas, v.3, n.2, p. 65-79, 2004. Originalmente publicado na HBR, 2004.

IEMI. Brasil Têxtil 2011. Relatório Setorial da Industria Têxtil Brasileira. Instituto de Estudos e Marketing Industrial, 2011.

KOZLOWSKI, A.; BARDECKI, M.; SEARCY, C. Environmental Impacts in the Fashion Industry: A Life-cycle and Stakeholder Framework. Journal Of Corporate Citizenship v. 45, p. 17-36, 2012.

LIPOVETSKY, G. O Império do Efêmero: A Moda e seu Destino nas Sociedades Modernas. São Paulo: Companhia das Letras, 1989.

LÖBACH, B. Design Industrial: Bases para a Configuração dos Produtos Industriais. Cap. 8. São Paulo: Editora Blutcher, São Paulo, 2001.

MANZINI, E.; VEZZOLI, C. O Desenvolvimento de Produtos Sustentáveis: os Requisitos Ambientais dos Produtos Industriais. São Paulo: EdUSP, 2002.

MALONI, M.; BROWN, M. Corporate Social Responsibility In The Supply Chain: An Application In The Food Industry. Journal of Business Ethics, v.68, p. 35-52, 2006.

MCDONOUGH, W.; BRAUNGART, M. Cradle to Cradle: Remaking the Way We Make Things. London: North Point Press, 2008, Kindle Edition, Chaps. 1 and 3. 
MILAN, G.; VITTORAZZI, C.; REIS, Z. A Redução de Resíduos Têxteis e de Impactos Ambientais: Um Estudo Desenvolvido em uma Indústria de Confecções do Vestuário. In: Seminários em Administração. XVIII SemeAd, Escola de Administração de Empresas, Faculdade de Economia e Administração, São Paulo, 2010.

Disponível

em:

http://www.ead.fea.usp.br/semead/13semead/resultado/trabalhosPDF/282.pdf Acesso em

PLATCHECK, E. R. Design Industrial - Metodologia de EcoDesign para o Desenvolvimento de Produtos Sustentáveis. Cap. 1. São Paulo: Ed. Atlas, 2012.

PORTER, M. Vantagem Competitiva, Criando e Sustentando um Desempenho Superior. $7^{\text {a }}$ edição, Cap. 2. Rio de Janeiro: Elsevier, 1992.

PORTER, M.; KRAMER, M. Creating Shared Value. Havard Business Review, v. 89, n. $1 / 2$, p. $62-77,2011$.

PORTER, M.; VAN DER LINDE, C. Green and Competitive: Ending the Stalemate. Harvard Business Review, v.73, n. 5, p. 120-134, 1995.

RIEPLE, A.; GANDER, J. Product Development Within a Clustered Environment: The Case of Apparel design firms. Creative Industries Journal, v.2, n. 3, p. 273-289, 2009.

SACHS, I. Rumo a Ecossocioeconomia. Rio de Janeiro: Cortez, 2007.

SAVITZ, S. A Empresa Sustentável: o Verdadeiro Sucesso é o Lucro com Responsabilidade Social e Ambiental. Rio de Janeiro: Elsevier, 2007.

SEURING, S. Industrial Ecology, Life Cycles, Supply Chains: Differences and Interrelations. Business Strategy and the Environment, v.13, p. 306-319, 2004.

SHRIVASTAVA, P.; HART, S. Greening Organizations. Academy of Management Best Papers Proceedings, p. 185-189, 1992.

SOUSA, A.; ALMEIDA, R. O Valor da Empresa e a Influência dos Stakeholders. São Paulo: Saraiva, 2006. 
YIN, R. K. Estudo de Caso: planejamento e métodos.3. Ed. Porto Alegre: Bookman, 2005.

ZYLBERSZTAJN, D.; LINS, C. Sustentabilidade e Geração de valor: a transição para o século XXI. Rio de Janeiro: Elsevier, 2010. 